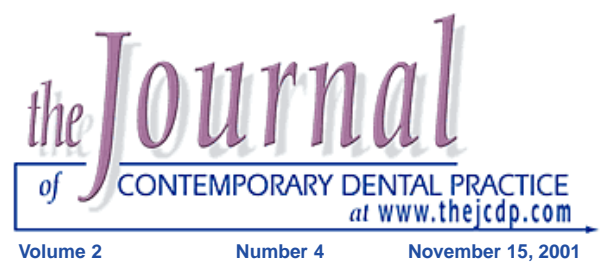

\title{
Case Report: Occult Maxillofacial Trauma in Epilepsy
}

\section{Cecilia E. Aragon, DDS; Jorge G. Burneo, MD; Joseph Helman, DDS}

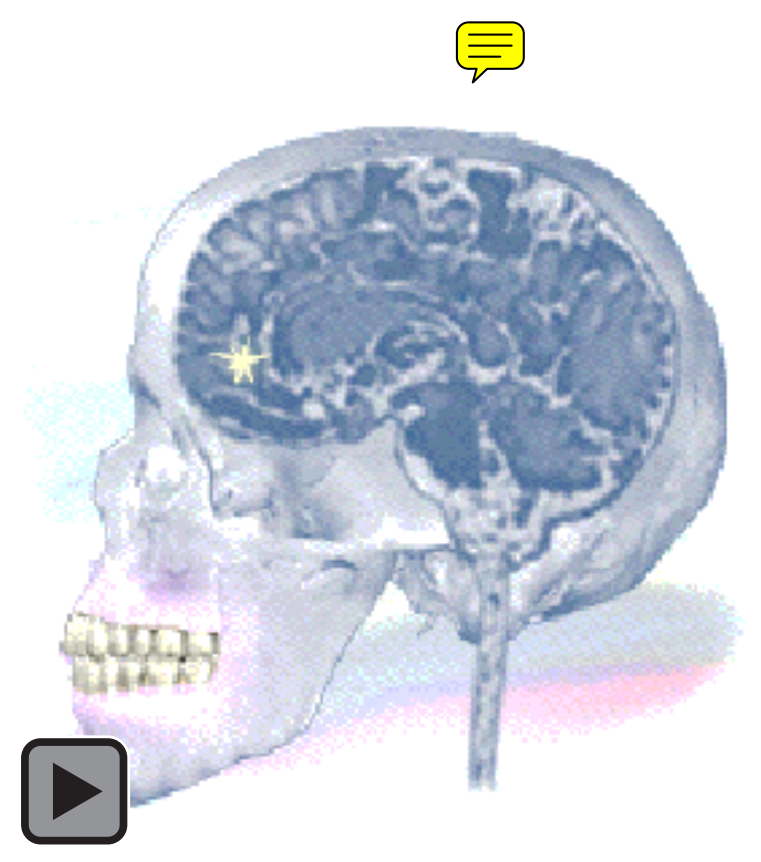

\begin{abstract}
Epilepsy is a relatively common neurological disorder with incidence in both developed and developing countries. Head, facial, and oral injuries can result from seizures experienced by the epileptic patient. Patients with severe epilepsy often experience other dental disease due to their inability to properly maintain their oral hygiene. This paper presents a case of a chronic mandibular fracture following an episode of seizures in a patient with epilepsy in whom the fracture was discovered when he developed a fistula in the submandibular region.

Keywords: Epilepsy, seizure, maxillofacial trauma

Citation: Aragon CE, Burneo JG, Helman J. Occult Maxillofacial Trauma in Epilepsy. J Contemp Dent Pract 2001 Nov;(2)4: 026-032.
\end{abstract}

(c) Seer Publishing 


\section{Background}

Epilepsy is a relatively common neurological disorder with an incidence of 40-70 per 100,000 in developed countries, and as high as 100-190 per 100,000 in developing countries.

Studies have demonstrated that $1.5-5.0 \%$ of the population will have a seizure at some time. ${ }^{2}$

Mortality and morbidity due to epilepsy is higher than in the general population. The real incidence of injuries due to this condition is still uncertain, but is gaining more attention in the literature. ${ }^{3}$

From recent studies, the most common types of injury following a seizure are head injuries, fractures, burns, and dental injuries. ${ }^{4,5}$ However, head injury is the topic that brings most of the attention to the investigators of this problem. Only one study $^{6}$ done in Africa revealed that the prevalence of dental/oral trauma can be as high as $46.4 \%$ in patients with epilepsy, but there is still a lack of information regarding occult oral and maxillofacial traumas.

This paper presents a case of a chronic mandibular fracture following an episode of seizures in a patient with epilepsy in whom the fracture was discovered when he developed a fistula in the submandibular region.

\section{Case Report}

A 56-year old man presented to an oral surgeon with a fistula in the right side of his neck that was found to be related to a mandibular fracture. Clindamycin was prescribed and he was referred to the University of Michigan Hospital for further treatment. Upon arrival he was found with an infected right mandibular fracture with the presence of a fistula in the right upper neck, a malunion of a previous fracture of the left mandibular angle, and multiple carious teeth. Radiological studies confirmed the diagnosis as well as revealed the presence of severe bone loss in the patient's dentition and surrounding supportive structure. (Figure 1)
His past medical history is remarkable for epilepsy, characterized by complex partial seizures and the

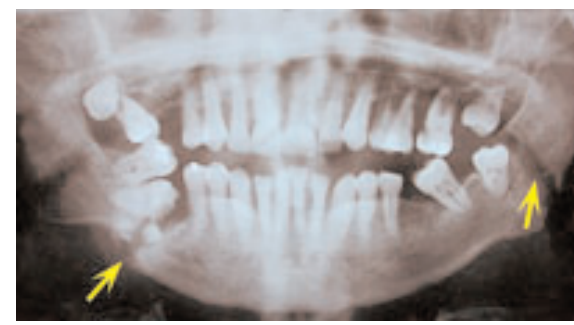
presence of mild mental retardation. The patient was being treated with lamotrigine, phenytoin, and phenobarbital. There was no historical evidence of a traumatic event that led to this fracture, other than a previous episode of seizures.

An open reduction and internal fixation of the bilateral mandibular fractures as well as maxillomandibular fixation procedures were performed. Excision of the right neck fistula and extraction of multiple teeth were also carried out. In the post-operative period, the patient continued with antibiotic treatment and had a satisfactory and unremarkable recovery.

\section{Discussion}

The most outstanding feature of this case is the presence of an asymptomatic mandibule fracture that remained asymptomatic and finally was manifested by a fistula in the neck. The factors that may be responsible for this oral trauma that was non-evident acutely were most likely the presence of mild mental retardation with subsequent diminished cognitive ability along with the benign presentation of this fracture.

Patients with epilepsy have an increased predilection for anterior dental injuries due to the falls that sometimes accompany seizures $^{6,7,8}$, but the presence of mandibular fractures have also been reported in the medical literature. $^{9}$

Self-care is essential to maintain oral health, but in many patients with epilepsy this is neglected due to the lack of a supportive environment as well as the mental and intellectual deterioration that is often present in cases with severe epilepsy. Some patients with epilepsy may not consider dental health a priority in their overall care because they are overwhelmed by their seizures and resulting psychosocial consequences. 


\section{Conclusion}

To maintain oral health there is a need for effective interaction between medical and dental practitioners in treating patients with disorders like epilepsy. ${ }^{10}$ Oral health should be stressed by the neurologist or the primary doctor in order to maintain long-term masticatory function and the obviously associated quality of life.

\section{References}

1. Sander JW, Shorvon SD. Epidemiology of the epilepsies. J Neurol Neurosurg Psychiatry. 1996 Nov;61(5):433-43. Review. No abstract available.

2. Trescher WH, Lesser RP. The Epilepsies. In: Bradley WG, Daroff RB, Fenichel GM, Marsden CD. Neurology in Clinical Practice. Pg 1746. Ed Butterworth-Heinemann, 2000.

3. Kirby S, Sadler RM. Injury and death as a result of seizures. Epilepsia. 1995 Jan;36(1):25-8.

4. Buck D, Baker GA, Jacoby A, Smith DF, Chadwick DW. Patients' experiences of injury as a result of epilepsy. Epilepsia. 1997 Apr;38(4):439-44.

5. Nakken KO, Lossius R. Seizure-related injuries in multihandicapped patients with therapy-resistant epilepsy. Epilepsia. 1993 Sep-Oct;34(5):836-40.

6. Ogunbodede EO, Adamolekun B, Akintomide AO. Oral health and dental treatment needs in Nigerian patients with epilepsy. Epilepsia. 1998 Jun;39(6):590-4.

7. Garcia-Godoy F, Dipres FM, Lora IM, Vidal ED. Traumatic dental injuries in children from private and public schools. Community Dent Oral Epidemiol. 1986 Oct;14(5):287-90.

8. Henshaw NE, Adenubi JO. Traumatized incisors in Nigerian children (abstract). W Afr J Surg 1980; 4: 50-5.

9. Zachariades N. Recurrent fractures of the mandible. Oral Surg Oral Med Oral Pathol. 1985 Nov;60(5):562-4. No abstract available.

10. Sanders BJ, Weddell JA, Dodge NN. Managing patients who have seizure disorders: dental and medical issues. J Am Dent Assoc. 1995 Dec;126(12):1641-7. Review.

\section{About the Author}

\section{Cecilia E. Aragon, DDS}

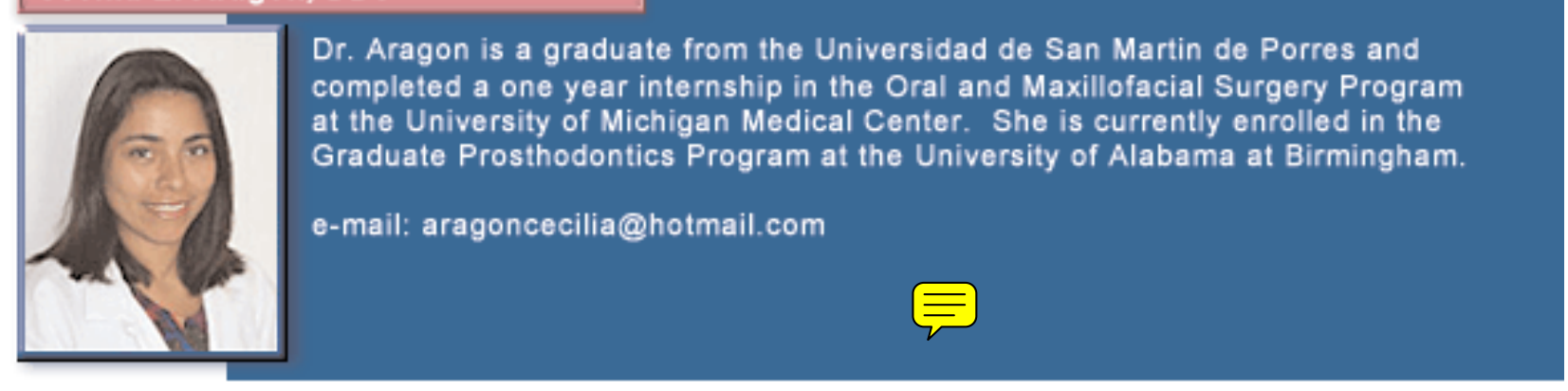

